\title{
Calculation of Surrounding Rock Pressure Based on Pressure Arch Theory
}

\author{
Yuxiang SONG ${ }^{1,2, \text { a }}$ \\ ${ }^{1}$ School of Civil Engineering, Southwest Jiaotong University, Chengdu 610031, China; \\ ${ }^{2}$ School of Civil Engineering, Shijiazhuang Tiedao University, Shijiazhuang 050043, China; \\ asongyuxiang36262@163.com
}

Keywords: critical buried depth, surrounding rock pressure, regression analysis, multivariate

\begin{abstract}
Study on the surrounding rock pressures of rail tunnel is conducted based on pressure arch theory by performing numerical simulation in this paper. Two concepts: the critical burial depth of arching and the boundary calculation of pressure arch, are proposed by analyzing the stress state above the vault. Based on the universal reference drawings of rail tunnel, influences of the span and buried depth of tunnel, as well as the physical and mechanical parameters of surrounding rock, on the critical buried depth and calculation boundary of pressure arch are investigated. Results indicate that the critical buried depth and calculation boundary of pressure arch increase with the increases in tunnel span and surrounding rock level, and certain laws are presented. The formulas of critical buried depth and calculation boundary of pressure arches are obtained by nonlinear multivariate regression analysis, and then, the formula of surrounding rock pressure is proposed based on the basic theory of pressure arch. Results of surrounding rock pressure predicted with the proposed formula and the formula in code for design of railway tunnel are compared. Comparison results indicate the surrounding rock pressure predicted with the proposed formula is larger than that with the formula in Chinese code; with the increase in surrounding rock level, the difference of predictions with the two formulas decreases, and is the smallest for surrounding rock with level $\mathrm{V}$.
\end{abstract}

\section{Introduction}

According to the characteristics of design for underground structures, available design and calculation models can be classified into four types: experience analogy model, load-structure model, layer-structure model and convergence constraint model. For load-structure model, the determination of surrounding rock pressure is a key factor in reasonable design. At present, the commonly used calculation methods are theoretical calculation method and empirical method. For these calculation methods, some do not take full account of the self-supporting capacity of rock, and some need to determine many parameters, which all restricts the application of these methods in practical engineering.

The existence of pressure arch after the excavation of formation has been confirmed by many engineering practice. М•М•Протодьяконов pressure arch theory has been used for over a hundred years in engineering practice. For this theory, pressure arch is deduced based on the bulk solid, which needs determining the consistent coefficient of formation, so the application of this theory is rather inconvenient. In this paper, according to the elastic-plastic theory, the arching conditions and the scope of pressure arch were analyzed, and the practical formula of surrounding rock pressure with the surrounding rock level and tunnel width in account, was proposed by using numerical simulation method, after considering main influence factors: hole span, buried depth and the nature of surrounding rock.

\section{Forming principle of pressure arch}

Before the excavating of cavern, rock is in a complex initial stress state. Unlike arch structures on the ground, the arching effect in surrounding rock is proposed in terms of pressure field. Although the 
pressure arch phenomenon is not easy to be observed, it is an objective reality. The form of pressure arch is constantly changed as the excavation is preceded, which, in fact, is the process that the stress in surrounding rock is redistributed and the rock reaches a steady state. Pressure arch effect presents not only in the tunnel vault, but also around the tunnel, such as the haunch and the invert. The role of rocks in pressure arch is to smoothly transfer the load on and after the arch to the stable medium in and around skewback.

The pressure arch of surrounding rock is the region with high surrounding rock stress, i.e. load-bearing areas in surrounding rock. Therefore, the area and scope of pressure arch can be determined according to the stress distribution in the surrounding rock.

Since the feature of formation for pressure arch can be clearly observed from the vector graph of principal stress, the vector graphs before and after the excavation of tunnels are compared. Figures 1 and 2 are two comparing vector graphs obtained by numerical simulation, in which the black arrows represent the maximum principal stress.

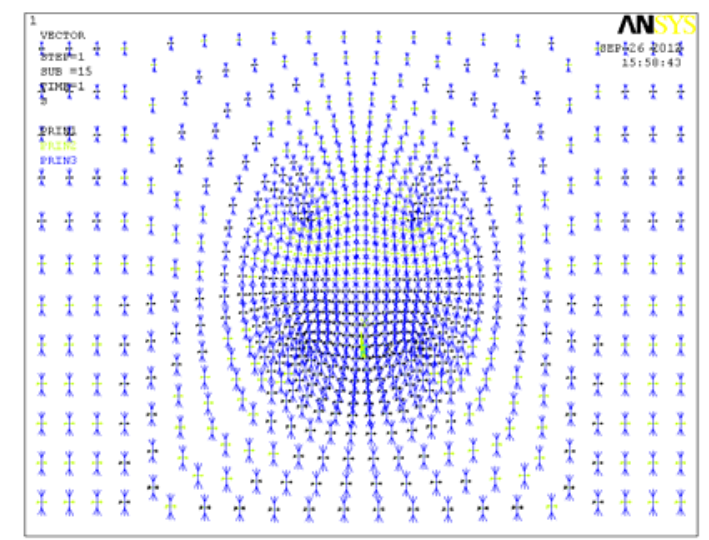

Fig.1 vector graph before the excavation of tunnel

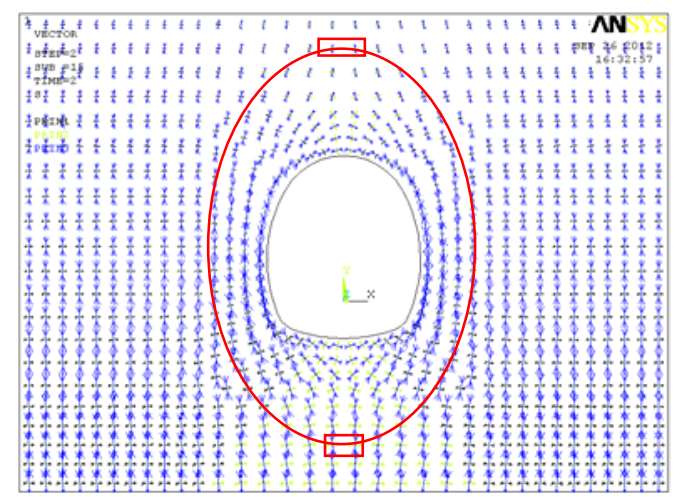

Fig. 2 vector graph after the excavation of tunnel

Figure 1 shows the self-weight stress field with the tectonic stress ignored before the tunnel is excavated. From this figure, it can be seen that the vertical stress is greater than the horizontal stress, and the maximum principal stress in the surrounding rock is in the vertical direction. After the tunnel is excavated, radial stresses in surrounding rock decrease, and tangential stresses increase, i.e., the radial stresses are transferred to the tangential direction. The direction of principal stress in the surrounding rock around the tunnel changes, and the direction of streamline distribution for the maximum principal stress presents ring form, as shown in the red elliptical loop of Figure 2. So, it can be concluded that pressure arch phenomenon exists in the surrounding rock around the tunnel. Consider the region above the vault. The tangential stresses near the wall of tunnel are concentrated due to the release of radial stresses, which results in the maximum principal stress direction changed into horizontal direction. As the position is far away from the wall, the level of stresses decreases while the vertical stresses gradually increase, and finally, the vertical stresses are the maximum principal stress again. The small box in Figure 2 indicates the nodes where the direction of the 
maximum principal stress is changed from horizontal to vertical direction, i.e., the maximum principal stresses in the region above vault present nearly $90^{\circ}$ deflection.

It can be confirmed that pressure arch phenomenon exists in the surrounding rock around the tunnel after excavating. The loads acting on the rear and upside of pressure arch are smoothly transferred to the stable rock at arch foot and surrounding pressure arch, and the support structure only withstand the load of surrounding rock in the range of pressure arch. Pressure arch has the mechanical properties of arch, and can prevent the surrounding rock above the arch from collapsing, so, it is a force mode favorable to the stability of surrounding rock.

\section{Numerical simulation of pressure arch}

(1) Calculation model and parameters

Numerical simulation is performed by using ANSYS software with plane strain model. Calculation section is determined according to the universal standard drawings of rail tunnel. The calculation boundary is taken as $5 \mathrm{D}(\mathrm{D}=$ tunnel excavation span) in the left and right sides, as well as the invert, respectively. The above boundary is taken as the analog depth of tunnel. Left and right boundaries are applied by the horizontal constraints at corresponding directions. The lower boundary is simulated with vertical boundary constraint, while upper boundary is free surface. Formation is assumed as elastic-perfectly plastic material, and follows Drucker-Prager yield criterion. The entire calculation model is shown in Figure 3

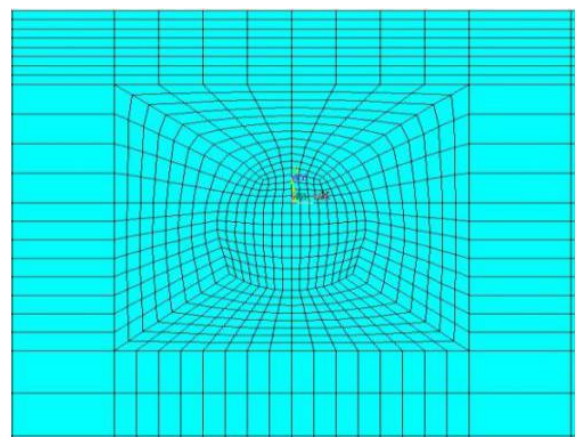

Fig. 3 Calculation model of Numerical simulation

(2) Critical buried depth and calculation boundary

Study is conducted based on universal standard drawings of single line tunnel for $200 \mathrm{~km} / \mathrm{h}$ mixed passenger and freight railway with III-level surrounding rock. The width and height of tunnel excavation are $8.86 \mathrm{~m}$ and $10.18 \mathrm{~m}$. Different buried depths: $8 \mathrm{~m}, 12 \mathrm{~m}, 16 \mathrm{~m}, 50 \mathrm{~m}, 100 \mathrm{~m}$ and $200 \mathrm{~m}$ are used for comparison in numerical simulation. After the path of stress above the vault is analyzed, the path curves of horizontal and vertical stresses shown in Figure 4 can be obtained.

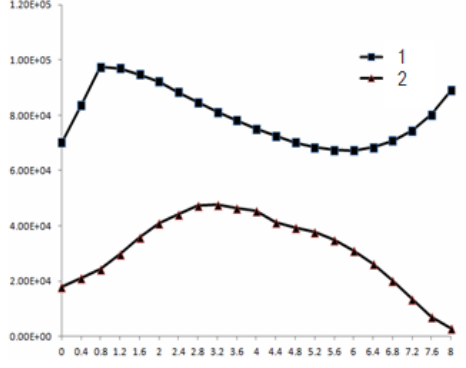

(a) Buried depths: $8 \mathrm{~m}$

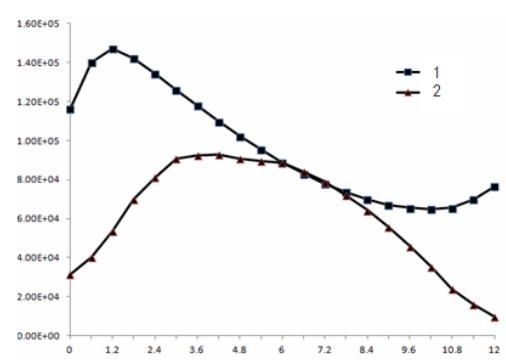

(b) Buried depths: $12 \mathrm{~m}$

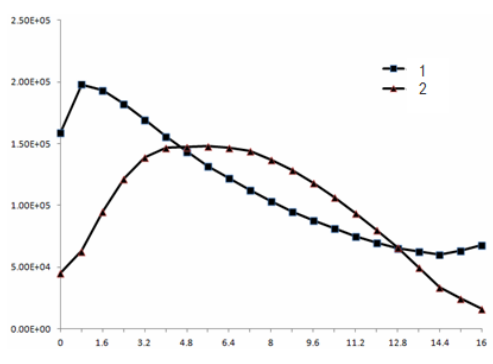

(c) Buried depths: $16 \mathrm{~m}$

1- The Level Secondary Rock Stress

2- The Vertical Secondary Rock Stress

Fig.4 Stress path curves of III-level surrounding rock

From figure 4 , it can be seen that when the tunnel is buried in shallow depth $(8 \mathrm{~m})$, there is no intersection between the horizontal and vertical stress quadratic curves at the vault of pressure arch, 
that is, no stress deflection occurs until the horizontal stress on the surface level has been the maximum principal stress, which reveals that arch body is restricted by ground surface, and no stable pressure arch is formed. With the depth increasing (higher than $12 \mathrm{~m}$ ), the intersection points appear between the horizontal and vertical stress quadratic curves, that is, a stable pressure arch is formed due to the deflection of quadratic curves. And in this case, the maximum principal stress in the pressure arch is in horizontal direction, while the maximum principal stress in the pressure arch is restored to initial vertical direction. The buried depth of tunnel, corresponding to the first appearance of intersection, is the critical buried depth $H_{\text {cri }}$; and the distance from the intersection point to the wall of tunnel is taken as the calculation boundary of pressure arch $H_{\text {bound. }}$

\section{Influencing factors of pressure arch}

Numerical simulation is performed based on the universal reference drawings of rail tunnel (including $160 \mathrm{~km} / \mathrm{h}$ single/double passenger dedicated line; $250 \mathrm{~km} / \mathrm{h}$ and $350 \mathrm{~km} / \mathrm{h}$ single/double line tunnel). The physical and mechanical parameters of rocks are shown in Table 1, and the inner contour sizes of reference drawings are shown in Table 2.

Table 1 Mechanical parameters of surrounding rocks

\begin{tabular}{cccccc}
\hline $\begin{array}{c}\text { Surrounding } \\
\text { rock level }\end{array}$ & $\begin{array}{c}\text { Elastic } \\
\text { modulus } \\
/ \mathrm{GPa}\end{array}$ & Density $/ \mathrm{kg} \cdot \mathrm{m}^{-3}$ & Poisson ratio & Cohesion /MPa & $\begin{array}{c}\text { Internal friction } \\
\text { angle } /{ }^{\circ}\end{array}$ \\
\hline II & 26.5 & 2600 & 0.225 & 1.80 & 55 \\
III & 13 & 2400 & 0.275 & 1.10 & 44.5 \\
IV & 3.7 & 2150 & 0.325 & 0.45 & 33 \\
V & 1.5 & 1850 & 0.4 & 0.125 & 23.5 \\
\hline
\end{tabular}

Table 2 Inner contour sizes of reference drawings

\begin{tabular}{ccc}
\hline Tunnel type & Span $/ \mathrm{m}$ & Height $/ \mathrm{m}$ \\
\hline $160 \mathrm{~km} / \mathrm{h}$ single general cargo line & 8.24 & 10.22 \\
$160 \mathrm{~km} / \mathrm{h}$ double general cargo line & 12.46 & 11.22 \\
$200 \mathrm{~km} / \mathrm{h}$ single general cargo line & 8.86 & 10.18 \\
$200 \mathrm{~km} / \mathrm{h}$ double general cargo line & 12.86 & 10.81 \\
$250 \mathrm{~km} / \mathrm{h}$ single passenger dedicated line & 8.82 & 9.70 \\
$250 \mathrm{~km} / \mathrm{h}$ double passenger dedicated line & 13.86 & 11.60 \\
$350 \mathrm{~km} / \mathrm{h}$ single passenger dedicated line & 10.28 & 10.56 \\
$350 \mathrm{~km} / \mathrm{h}$ double passenger dedicated line & 14.10 & 11.73 \\
\hline
\end{tabular}

By analyzing the stress in paths above the vault, the values of $H_{\text {cri }}$ and $H_{\text {bound }}$ corresponding to different reference drawings (with different spans, different surrounding rock levels) are shown in Tables 3 and 4.

Table 3 Influence of surrounding rock level on $H_{\text {cri }}$ Unit: $\mathrm{m}$

\begin{tabular}{cccccc}
\hline Tunnel type & \multirow{2}{*}{ Span $/ \mathrm{m}$} & \multicolumn{3}{c}{ Surrounding rock level } \\
\cline { 3 - 5 } & & II & III & IV & $\mathrm{V}$ \\
\hline $160 \mathrm{~km} / \mathrm{h}$ single general cargo line & 8.24 & 10 & 12 & 14 & 18 \\
$250 \mathrm{~km} / \mathrm{h}$ single passenger dedicated line & 8.82 & 10.5 & 13 & 15 & 21 \\
$200 \mathrm{~km} / \mathrm{h}$ single general cargo line & 8.86 & 11.5 & 13 & 14.5 & 21 \\
$350 \mathrm{~km} / \mathrm{h}$ single passenger dedicated line & 10.28 & 14 & 15.5 & 17.5 & 22 \\
$160 \mathrm{~km} / \mathrm{h}$ double general cargo line & 12.46 & 17 & 19.5 & 21 & 27 \\
$200 \mathrm{~km} / \mathrm{h}$ double general cargo line & 12.86 & 17.5 & 19.5 & 22 & 28 \\
$250 \mathrm{~km} / \mathrm{h}$ double passenger dedicated line & 13.86 & 18 & 20 & 22.5 & 29 \\
$350 \mathrm{~km} / \mathrm{h}$ double passenger dedicated line & 14.10 & 18.5 & 20 & 23 & 30.5 \\
\hline
\end{tabular}


Table 4 Influence of surrounding rock level on $H_{\text {bound }}$ Unit: $m$

\begin{tabular}{cccccc}
\hline \multirow{2}{*}{ Tunnel type } & \multirow{2}{*}{ Span $/ \mathrm{m}$} & \multicolumn{3}{c}{ Surrounding rock level } \\
\cline { 3 - 6 } & & II & III & IV & V \\
\hline $160 \mathrm{~km} / \mathrm{h}$ single general cargo line & 8.24 & 4.1 & 5.0 & 5.7 & 11.1 \\
$250 \mathrm{~km} / \mathrm{h}$ single passenger dedicated line & 8.82 & 4.3 & 5.1 & 5.6 & 12.0 \\
$200 \mathrm{~km} / \mathrm{h}$ single general cargo line & 8.86 & 4.4 & 5.1 & 5.7 & 13.8 \\
$350 \mathrm{~km} / \mathrm{h}$ single passenger dedicated line & 10.28 & 4.8 & 5.3 & 6.0 & 14.3 \\
$160 \mathrm{~km} / \mathrm{h}$ double general cargo line & 12.46 & 5.2 & 5.7 & 6.2 & 14.2 \\
$200 \mathrm{~km} / \mathrm{h}$ double general cargo line & 12.86 & 5.4 & 6.2 & 6.8 & 14.6 \\
$250 \mathrm{~km} / \mathrm{h}$ double passenger dedicated line & 13.86 & 5.5 & 6.1 & 6.8 & 14.8 \\
$350 \mathrm{~km} / \mathrm{h}$ double passenger dedicated line & 14.10 & 6.4 & 8.1 & 9.1 & 16.2 \\
\hline
\end{tabular}

Results in table 3 and 4 indicate that the critical buried depth and calculation boundary of pressure arch increase with the increase in tunnel span; and for the same tunnel span, the critical buried depth and calculation boundary also increase with the stability of surrounding rock gradually weakening, which means that for weaker surrounding rock, larger buried depth is required to form pressure arch, and greater calculation boundary of pressure arch is determined.

\section{Influencing factors of pressure arch}

From the simulation results above, it can be seen that the main factors influencing the critical buried depth and calculation boundary of pressure arches are the tunnel span, as well as the physical and mechanical parameters of surrounding rock. Therefore, both critical buried depth and calculation boundary of pressure arches are fitted as a function of surrounding rock level and tunnel span, based on the theory of nonlinear multivariate regression analysis.

(1) Critical buried depth

The regression equation of critical buried depth is expressed as

$H_{\mathrm{Cri}}=k_{1} \times\left[k_{2}+k_{3} \times(B-5)\right] \times k_{4}{ }^{(\mathrm{s}-1)}$

where $\mathrm{B}$ is the tunnel span; $\mathrm{S}$ is the surrounding rock level; $k_{1} \sim k_{4}$ are the coefficients to be determined. By fitting calculation, the best-estimated results of parameters are: $k_{1}=1.562973$; $k_{2}=4.522932 ; k_{3}=0.62923$ and $k_{4}=1.130996$.

So, the regression equation above can be rewritten as

$H_{\mathrm{Cri}}=7 \times[1+0.13 \times(B-5)] \times 1.1^{(S-1)}$

The square of correlation coefficient for the fitted formula, $\mathrm{R}$, is 0.95 , which is larger than 0.9. So, the formula above can reasonably predict simulation results. Comparison between the results from numerical simulation and these predicted with the fitted formula, is shown in Figure 5.

(2) Calculation boundary

The regression equation of calculation boundary is expressed as:

$H_{\mathrm{Cal}}=k_{5} \times\left[k_{6}+0.1 \times(B-5)\right] \times k_{7}{ }^{(\mathrm{s}-1)}$

By fitting calculation, the best-estimated results of parameters in Eq. 3 are: $k_{5}=1.626811$;

$k_{6}=1.0220874$ and $k_{7}=1.499908$. So, Eq. 3 can be rewritten as

$H_{\mathrm{Cal}}=1.6 \times[1+0.1 \times(B-5)] \times 1.5^{(S-1)}$

The square of correlation coefficient for the fitted formula, $\mathrm{R}$, is 0.94 , which is also larger than 0.9 . So, the formula above can reasonably predict simulation results. Comparison between the simulated and predicted results is shown in Figure 6. 


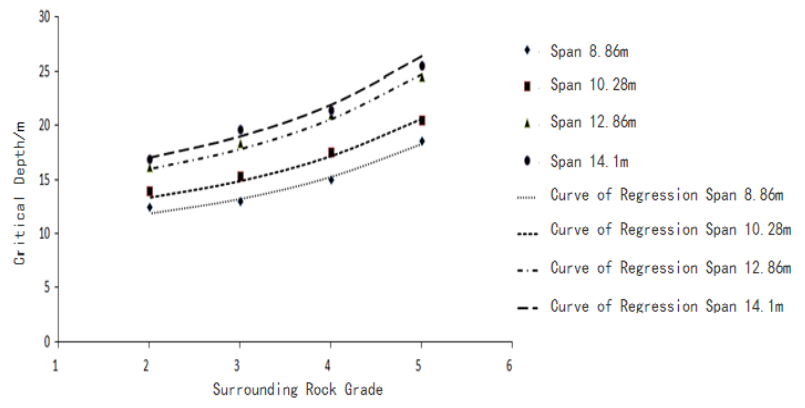

Fig5. Comparison between the simulated and predicted results of critical buried depth

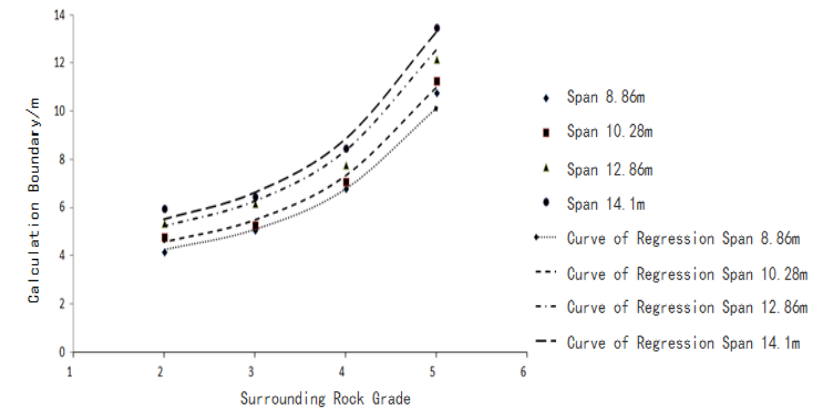

Fig6. Comparison between the simulated and predicted results of calculation boundary

\section{Formula of surrounding rock pressure}

According to the forming principle of pressure arch, the existence of pressure arch in surrounding tunnel after excavating can be confirmed. The loads acting on the rear and upside of pressure arch are smoothly transferred to the stable surrounding rocks at arch foot and around the pressure arch, and the support structure only withstand the load of surrounding rock in the range of pressure arch. So, based on pressure arch theory, the formula of surrounding rock pressure is proposed as:

$q=\gamma h=\gamma \times 1.6 \times[1+0.1 \times(B-5)] \times 1.5^{(S-1)}$

where $\gamma$ is the unit weight of surrounding rock.

Consider the universal drawings of single line tunnel for $200 \mathrm{~km} / \mathrm{h}$ mixed passenger and freight railway. Results of the surrounding rock pressure for deep-buried tunnels predicted with the formula proposed in this paper and the formula in code for design of railway tunnel are compared in Table 5 and Figure 7.

Table 5 Predictions of vertical surrounding rock pressure for different surrounding rock levels

\begin{tabular}{ccc}
\hline Surrounding rock levels & $\begin{array}{c}\text { With the formula in Chinese code } \\
/ \mathrm{kPa}\end{array}$ & With the proposed formula $/ \mathrm{kPa}$ \\
\hline II & 30.42 & 86.4864 \\
III & 59.88 & 119.7504 \\
IV & 110.37 & 160.9146 \\
V & 191.27 & 207.6921 \\
\hline
\end{tabular}

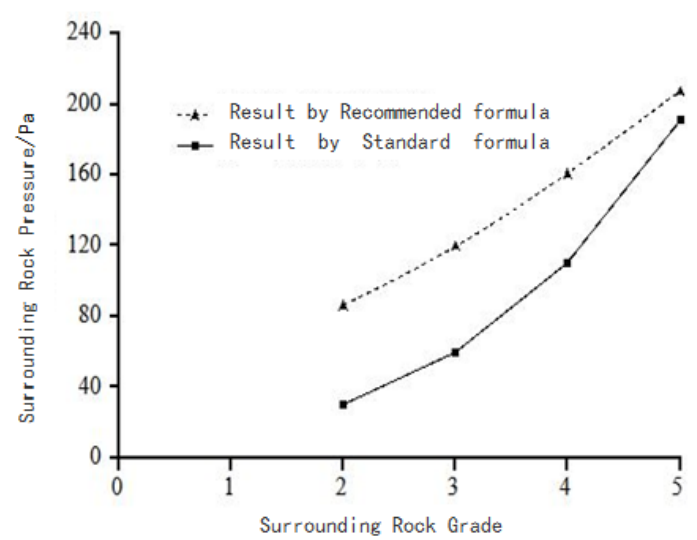

Fig.7 Comparison of results predicted with the formula in Chinese code and Eq.5

From the results shown in Table 5 and Fig. 7, it can be seen that when the level of surrounding rock is low, which indicates good stability, the rock pressure predicted with the proposed formula is larger than that with the formula in Chinese code; when the level of surrounding rock increases (IV $\sim \mathrm{V}$ grade), indicating weaker stability, the difference of predictions with the two formulas decreases. 


\section{Conclusions}

(1) By comparing the main stress vector diagrams before and after the excavating of tunnel, the existence of pressure arch in surrounding tunnel after excavating is confirmed. The loads acting on the rear and upside of pressure arch are smoothly transferred to the stable surrounding rocks at arch foot and around the pressure arch, and the support structure only withstand the load of surrounding rock in the range of pressure arch.

(2) Results of numerical simulation indicate that when the tunnel is buried in shallow depth, the principal stress at the vault of pressure arch deflects after the excavating of tunnel, and there is no intersection between the horizontal and vertical stress quadratic curves, that is, no pressure arch is formed until the horizontal stress on the surface level has been the maximum principal stress. With the depth increasing, the intersection appeared between the horizontal and vertical stress quadratic curves, that is, a stable pressure arch is formed due to the deflection of quadratic curves. The buried depth of tunnel, corresponding to the first appearance of intersection, is the critical buried depth $H_{\text {cri }}$; and the distance from the intersection point to the wall of tunnel is taken as the calculation boundary of pressure arch $H_{\text {bound. }}$

(3) Based on the universal reference drawings of rail tunnel, influences of the span and buried depth of tunnel, as well as the physical and mechanical parameters of surrounding rock, on the critical buried depth and calculation boundary of pressure arch are investigated. Results indicate that the critical buried depth and calculation boundary of pressure arch increase with the increase of tunnel span; and when the level of surrounding rock increases, which indicates the stability of surrounding rock is gradually weaken, the critical buried depth and calculation boundary are also increased.

(4) Based on the theory of nonlinear multivariate regression analysis, both critical buried depth $H_{\mathrm{cti}}$ and calculation boundary, $H_{\text {bound }}$ of pressure arch are fitted as a function of surrounding rock level $S$ and tunnel span $B$

$$
\begin{aligned}
& H_{\text {cti }}=7 \times[1+0.13 \times(B-5)] \times 1.1^{(S-1)} \\
& H_{\text {bound }}=1.6 \times[1+0.1 \times(B-5)] \times 1.5^{(S-1)}
\end{aligned}
$$

(5) Based on the basic principle of pressure arch, the formula of surrounding rock pressure is proposed. The rock pressure predicted with the proposed formula is larger than that with the formula in code for design of railway tunnel; With the increase of surrounding rock level, the difference of predictions with the two formulas decreases, and is the smallest for surrounding rock with level V.

\section{References}

[1]. Wang Chuang. Research on pressure arch in large span underground rock engineering. China University of Mining and technology. 2003.

[2]. Zhu Zheng-guo. Research on surrounding rock pressure calculating method and dynamic construction mechanical behavior of multi-arch tunnel. Beijing: Beijing Jiao Tong University, 2007.

[3]. Bi Ji-hong, Zhong Jian-hui and Cong Rong. Shallow tunnel finite element analysis of rock pressure. Railway Engineering Society. Vol. 84 (2004) No. 4, p. 77-81.

[4]. Fu He-lin, Han Yu-cai and Zhu Han-hua. Broken arch tunnel wall rock single solution load of theoretical calculations. Central South University: Natural Science Edition. Vol. 35 (2004) No. 3, p. $478-483$.

[5]. Yang Xiao-li and Wang Zuo-wei. Limit shallow tunnel under nonlinear failure criterion of rock pressure analysis. Central South University: Natural Science Edition. Vol. 41 (2010) No. 1, p. 299-303.

[6]. Lin Le-bin, Liu Han-bing and Liu Hui. Tunnel rock pressure stress analysis method. China Civil Engineering Journal. Vol. 40 (2007) No. 8, p. 85-89. 
[7]. Qu Hai-feng and Yang Chong-cun. Deposit highway tunnel surrounding rock pressure research and development. Underground Space and Engineering. Vol. 3 (2007) No. 3, p. 536-543.

[8]. Song Hong-wei, Zhao Jian and Wang Chuang. Study on concept and characteristics of stress rock arch around a cavern underground. Proceedings of Underground Singapore 2003 and Workshop Updating the engineering geology of Singapore, Singapore, 2003, p. 44-51. 